\section{Feroxyhyte on Mars?}

BURNS discussion ${ }^{1}$ on the possibility of the mineral feroxyhyte occurring on the surface of Mars is potentially misleading. In the original description of this mineral Chukhrov et al. ${ }^{2}$, following Feitknecht ${ }^{3}$, distinguished between a strongly magnetic phase, $\delta$ - $\mathrm{FeOOH}$, and a "practically nonmagnetic" phase $\delta^{\prime}-\mathrm{FeOOH}$. It was the weakly or nonmagnetic $\delta^{\prime}$ phase to which the mineral name feroxyhyte was applied. Burns seems to have equated the two phases and uses data in support of his hypothesis most of which are derived from the synthetic $\delta$-FeOOH. The difference may be of more than semantic significance because the ferromagnetic, deep brownish $\delta$ - FeOOH is formed by the vigorous, rapid oxidation and topotactic replacement of $\mathrm{Fe}(\mathrm{OH})_{2}$. As this is a process unlikely to occur in natural conditions at the Earth's surface, $\delta$ - FeOOH has yet to be reported as a mineral. On the other hand, $\delta^{\prime}-\mathrm{FeOOH}$ (feroxyhyte), while also requiring the topotactic replacement of precipitated $\mathrm{Fe}(\mathrm{OH})_{2}$, is obtained by a slower oxidation and is a yellow-brown ocherous material when dried ${ }^{2}$. This is the mineral reported from marine sediments and gley soils ${ }^{2}$. The yellow-brown colour is almost identical to the description of the soils at the Viking Lander sites ${ }^{4}$. However, if feroxyhyte is nonmagnetic then its major presence on the weak magnets attached to the Viking Lander backhoes $^{5}$ is improbable. Chukhrov et al. noted that some of the $\delta^{\prime}-\mathrm{FeOOH}$ samples they studied contained admixed maghaemite $\left(\gamma-\mathrm{Fe}_{2} \mathrm{O}_{3}\right)$ which they felt contributed to the weak magnetism of these individual samples. Thus, on the basis of colour, feroxyhyte $\left(\delta^{\prime}-\mathrm{FeOOH}\right)$ might indeed be a constituent of the surface of Mars and the magnetic experiments may have picked up admixed maghaemite $^{s}$, but the possibility of $\delta$ $\mathrm{FeOOH}$ on Mars seems remote.

\section{KENNETH M. TOWE}

Department of Paleobiology,

Smithsonian Institution,

Washington DC 20560

1. Burns, R. G. Nature 285,647 (1980).

2. Chukhrov, F. V. et al. Int. Geol. Rev. 19, 873-890 (1977).

3. Feitknecht, W. Z. Elektrochem. 63, 34-43 (1959)

4. Huck, F. O. et al. J. geophys. Res. 82, 4401-4411 (1977)

4. Huck, F. O. et al. J. geophys. Res, 82, $4401-4411$ (1977). Hargraves, R. B., Collinson, D. W., Arvidson, R. E. \&
Spitzer, C. R. J. geophys. Res. 82, 4547-4558 (1977).

BURNS REPLIES-When it was suggested that feroxyhyte might occur on the surface of Mars', I was well aware ${ }^{2,3}$ of the claimed distinction between the ferromagnetic phase $\delta-\mathrm{FeOOH}$ and the terrestrial mineral feroxyhyte $\left(\boldsymbol{\delta}^{\prime}-\mathrm{FeOOH}\right)$. Towe points out that in their original descriptions of feroxyhyte, Chukhrov et al. thought the weak magnetism in some $\delta^{\prime}-\mathrm{FeOOH}$ samples was due to maghaemite $\left(\gamma-\mathrm{Fe}_{2} \mathrm{O}_{3}\right)$ impurities ${ }^{4,5}$. Note, however, that synthetic $\delta$-FeOOH phases display variable saturation magnetization ${ }^{6-13,17}$ as a result of particle size variations, implying the coexistence of $\delta$-FeOOH and $\delta^{\prime}-\mathrm{FeOOH}$ in most synthesis products. Maghaemite, too, shows similar tendencies towards superparamagnetism ${ }^{14-16}$. Towe has focused his attention on the magnetic properties of $\delta-\mathrm{FeOOH}-\delta^{\prime}-\mathrm{FeOOH}$ assemblages without commenting on other favourable properties of them relevant to martian geochemistry. I contend that feroxyhyte $\delta^{\prime}-\mathrm{FeOOH}-\delta$ - FeOOH admixtures must be reckoned as a prime candidate for the colour, chemisorption, spectral, redox, paragenesis and magnetic properties of the surface of Mars.

\section{Department of Earth and}

ROGER G. BURNS

Planetary Sciences,

Massachusetts Institute of

Technology,

Cambridge, Massachusetts 02139

1. Burns, R. G. Nature 285, 647 (1980).

2. Burns, R. G. (ed.) Marine Minerals, Ch. 2 (Mineralogical Society of America Monograph 6, 1979)

3. Burns, R. G. \& Burns, V. M. in The Sea Vol. 7 led. Emiliani, C.) (Wiley-Interscience, New York, in the press).

4. Chukhrov, F. V. et al. Izv. Akad. Nauk SSR, Ser. geol. no. 5, 5 (1976); Int. geol. Rev. 19, 873 (1977).

5. Chukhrov, F. V., Zvyagin, B. B., Yermilova, L. P. \& Gorshkov, A. I. Miner. Depos. 11, 24 (1976).

6. Okamoto, S. J. Am. ceram. Soc. 51, 594 (1968).

7. Kulgawczuk, D. S., Obuszko, A. \& Szytula, A. Phys. Status Solidi 26, K83 (1968)

8. Dezsi, I., Keszthelyi, L., Kulgawczuk, D., Moinar, B. Eissa N. A. Phys. Status Solidi 22, 617 (1967).

9. Feitknecht, W., Haeni, H. \& Dvorak, V. Proc. 6th Int. Symp. on Reactivity in Solids, 237 (Wiley-Interscience, New York, 1969).

10. Sara, J. Chem. Listy 63, 112 (1969).

11. Vlasov, A. Ya., Loseva, G. V. \& Murashko, N. V. Izv. Vyssh. ucheb. Zaved. Fiz. 13, 129 (1970).

12. Loseva, G. V., Murashko, N. V. Izv. Akad. Nauk. SSSR Neorg. Mater. 7, 1467 (1971)

13. Kukoz, F. I., Emets, A. A. Trudy novocherk. politekh. Inst. No. 269, 61 (1972).

14. Coey, J. M. D. Phys. Rev. Lett. 27, 1140 (1971).

15. Coey, J. M. D. \& Khalafala, D. Phys. Status Solidi 11, 229 (1972).

16. Shipin'kov, N. I., Olefirenko, P. P. Soviet Phys. Solid State 20, 222 (1978).

17. Muller, O., Wilson, R. \& Krakow, W. J. Mater. Sci. 14, 2929 (1979).

\section{Anisotropy of \\ Young's modulus of bone}

The Hashin-Rosen model was recently applied by $\mathrm{Katz}^{1}$ to bone to explain the variation of Young's modulus, $E$, for bovine femoral specimen with respect to the orientation of specimen axes cut at the angle $\phi$ to the long axis of the bone. From Fig. 4 of Katz's report it can be seen that $(1)$ in the case of dry bones $E$ fell from $20 \mathrm{GN} \mathrm{m}^{2}$ at $0^{\circ}$ to 13 at $10^{\circ}$. At $20^{\circ}, 50^{\circ}$, $60^{\circ}$ and $70^{\circ} \mathrm{E}$ was 13 . Only at $30^{\circ}$ and $40^{\circ}$ was it 14 ; (2) in the case of wet bone $E$ was $17 \mathrm{GN} \mathrm{m}^{2}$ at $0^{\circ}$ then fell steadily to 10 at $50^{\circ}$. $E$ then increased to 14 at $60^{\circ}$, remained steady at 14 up to $70^{\circ}$ and thereafter gradually declined to about $11 \mathrm{GN} \mathrm{m}^{-2}$.

If values of $E$ for the dry and wet bone specimens are considered to be significantly different, water must have an important role in determining the mechanical properties of bone. The Hashin-Rosen model does not take this role into account.
If, on the other hand, values of $E$ for the dry and wet bone specimens are not considered to be significantly different, $E$ values between $10^{\circ}$ to $80^{\circ}$ lie between 13 and $14 \mathrm{GN} \mathrm{m}^{-2}$, that is, $E$ does not seem to be affected by $\phi$. This result is contrary to the Hashin-Rosen model. Accordingly, I wonder whether the Hashin-Rosen model can be profitably applied to bone.

S. CHATtERJI

\section{Research and Development,}

$1 A$, Lundtoftevej, DK-2800 Lyngby,

Denmark

1. Katz, Nature 283, 106 (1980).

KATZ REPLIES-Further explanation seems necessary for the role of the Hashin-Rosen calculation in modelling the elastic properties of bone. This is the structural composite phase of the hierarchical modelling. It cannot per se account for the effects of wet compared with dry bone. This entails considering the material composite nature of the system during the hierarchical modelling.

First, as I stated ${ }^{1}$, dry bone is stiffer and more rigid than the same specimen when wet. This is attributed to changes in the elastic properties of the organic matrix of bone. Second, the Young's modulus, $E$, of bone does vary with angle $\phi$ as shown by many experimenters for haversian bone, for so-called plexiform bone and for mixed specimens. The bovine bone specimens used by Bonfield and Grynpas ${ }^{2}$ probably included all three kinds; unfortunately, they reported no structural observations. Indeed, this might explain why some wet specimens were stiffer than some dry ones (plexiform bone is stiffer than haversian bone).

These facts can be incorporated in the Hashin-Rosen calculation; values of $E_{\mathrm{GS}}$, $\nu_{\mathrm{GS}}, E_{\text {Ost }}$ and $\nu_{\text {Ost }}$ can be adjusted. Thus, $E(\phi)$ in Fig. 3 of my report is approximately $30 \%$ greater than the equivalent $E(\phi)$ on Fig. 4. Also, $E(\phi)$ at any angle $\phi$ can vary as much as $80 \%$ (see Fig. 4 of ref. 1) simply by altering the percentage of longitudinal osteonic collagen fibres. Thus, curve $a$ of Fig. 4 simulates dry bone, and curves $b, c$ and $d$ in effect simulate wet bone behaviour. In reality, this calculation accounts for the effects of sample variation described above, that is, more longitudinal fibres, and thus stiffer lamellae, so simulating plexiform bone.

Unfortunately, my original report ${ }^{1}$ could not be expanded to discuss all this; a longer, more complete paper is being prepared. Finally, a hierarchical model wherein a structural composite is superimposed on a material composite does simulate the elastic properties of bone.

\section{J. LAWRENCE KATZ}

Rensselaer Polytechnic Institute,

Troy, New York 12181

1. Katz, J. L. Nature 283, 106-107 (1980).

2. Bonfleld, W. \& Grynpas, M. D. Nature 270, $453-454$ (1977). 